\title{
NUMERICAL ANALYSIS OF FRACTIONAL ORDER INTEGRAL DYNAMICAL MODELS WITH PIECEWISE CONTINUOUS KERNELS
}

\author{
A. Tynda ${ }^{1}$, D. Sidorov Si, $^{2,}$ I. Muftahov ${ }^{2,4}$ \\ ${ }^{1}$ Penza State University, Penza, Russian Federation \\ ${ }^{2}$ Melentiev Energy Systems Institute SB RAS, Irkutsk, Russian Federation \\ ${ }^{3}$ Irkutsk National Research Technical University, Irkutsk, Russian Federation \\ ${ }^{4}$ Main Computing Center of JSC Russian Railways, Irkutsk, Russian Federation \\ E-mails: tyndaan@mail.ru, sidorov@isem.irk.ru, ildar_sm@mail.ru
}

\begin{abstract}
Volterra integral equations find their application in many areas, including mathematical physics, control theory, mechanics, electrical engineering, and in various industries. In particular, dynamic Volterra models with discontinuous kernels are effectively used in power engineering to determine the operating modes of energy storage devices, as well as to solve the problem of load balancing. This article proposes the numerical scheme for solution of the fractional order linear Volterra integral equations of the first kind with piecewise continuous kernels. The developed approach is based on a polynomial collocation method and effectively approximate such a weakly singular integrals. The efficiency of proposed numerical scheme is illustrated by two examples.

Keywords: Volterra integral equations; numerical method; convergence; discontinuous kernel; singularity; fractional integral.
\end{abstract}

\section{Introduction}

Volterra integral equations (VIEs) [1] were introduced by Vito Volterra and then studied by Traian Lalescu in his 1908 thesis. In weakly regular case, VIEs were introduced in [2], and the theory of such equations is generalized to the case of systems of equations and to abstract operator equations in the monograph [3]. Integral equations are essential tools in various fields including power and electrical engineering, mathematical physics, control theory and mechanics.

Fractional integration and fractional differentiation are generalisations of notions of integer-order integration and differentiation, and include $n$-th derivatives and $n$-folded integrals ( $n$ denotes an integer number) as particular cases. The first mention of derivatives of non-integer order is presented in the correspondence between G. Leibniz and J. Bernoulli. In a letter written by G. Leibniz to G. Lopital, there is also an interesting mention about the paradox and possible useful practical application of differentials of order $\frac{1}{2}$. In recent years, interest in fractional calculus grows [4-6].

Fractional derivatives have numerous applications; they are in the core of various mathematical models for viscoelastic bodies, in chemical physics, the theory of gravity, viscoplasticity, etc. [6,7]. Fractional derivatives have practical applications in modelling the behavior of viscoplastic materials. In particular, the equations of state in the theory of viscoplasticity contain fractional derivatives and can be reduced to weakly singular Volterra integral equations of the second kind $[8,9]$. 
This article discusses weakly regular Volterra equations of the first kind

$$
\int_{0}^{t} K(t, s) x(s) d s=f(t), \quad 0 \leq s \leq t \leq T, f(0)=0,
$$

where the kernel is defined as follows:

$$
K(t, s)=\left\{\begin{array}{cl}
K_{1}(t, s), t, s \in m_{1}, & m_{i}=\left\{t, s \mid \alpha_{i-1}(t)<s<\alpha_{i}(t)\right\}, \\
\ldots \ldots \ldots \ldots & \\
K_{n}(t, s), t, s \in m_{n}, & \alpha_{0}(t)=0, \alpha_{n}(t)=t, i=\overline{1, n},
\end{array}\right.
$$

$\alpha_{i}(t), f(t) \in \mathcal{C}_{[0, T]}^{1}, K_{i}(t, s)$ have continuous derivatives with respect to $t$ for $\in \overline{m_{i}}$, $K_{n}(t, t) \neq 0, \alpha_{i}(0)=0,0<\alpha_{1}(t)<\alpha_{2}(t)<\ldots<\alpha_{n-1}(t)<t, \alpha_{1}(t), \ldots, \alpha_{n-1}(t)$ grow in a small neighborhood $0 \leq t \leq \tau, 0<\alpha_{1}^{\prime}(0) \leq \ldots \leq \alpha_{n-1}^{\prime}(0)<1$.

The works $[2,10]$ are the first to study such equations and to outline the non-uniqness of the solution. The paper [11] derives the existence of a continuous solution depending on free parameters as well as sufficient conditions for the existence of a unique continuous solution to the system of VIE of the first kind with discontinuous kernels. The class of Volterra operator equations of the first kind with piecewise continuous kernels is studied in [12]. Various numerical methods for linear and nonlinear VIE with piecewise continuous kernels and their systems with applications for power systems operation are proposed in [13-15]. In [16], the Volterra model is employed for a load leveling problem in modelling the hybrid AC/DC power systems with renewable energy sources and storage system.

For systematic studies of VIE of the first kind with piecewise continuous kernels, see the book [3] and the part 1 in [17]. For numerical solution of Volterra integral equation of Abel type, see [18]. The numerical solution of the Volterra fractional integral equations of the second kind using the Simpson 3/8 rule method is proposed in [4].

In the case of a fractional order of integration for these equations, consider the leftsided Riemann-Liouville fractional integral of the order $\beta \geq 0$

$$
I_{t}^{\beta} f(t)=\frac{1}{\Gamma(\beta)} \int_{0}^{t} \frac{f(s)}{(t-s)^{\beta}} d s .
$$

For equation (1) in the case of fractional order of integration (3), we solve the integral equation

$$
\frac{1}{\Gamma(\beta)} \int_{0}^{t} \frac{K(t, s)}{(t-s)^{\beta}} x(s) d s=f(t), \quad 0 \leq s \leq t \leq T, f(0)=0,
$$

with piecewise continuous kernel (2).

\section{Polynomial Collocation Method}

Let us write equation (4) in the following expanded form:

$$
\frac{1}{\Gamma(\beta)} \sum_{i=1}^{n} \int_{\alpha_{i-1}(t)}^{\alpha_{i}(t)} \frac{K_{i}(t, s) x(s)}{(t-s)^{\beta}} d s=f(t), \quad t \in[0, T], 0<\beta<1 .
$$


Apply the following representation (as power series segment) of the solution to equation (5):

$$
X_{m}(t)=\sum_{j=0}^{m} a_{j} t^{j}
$$

with the desired $a_{j}, j=0,1, \ldots, m$. Let us substitute (6) into (5), then we get

$$
\frac{1}{\Gamma(\beta)} \sum_{i=1}^{n} \int_{\alpha_{i-1}(t)}^{\alpha_{i}(t)} \frac{K_{i}(t, s)}{(t-s)^{\beta}}\left(\sum_{j=0}^{m} a_{j} s^{j}\right) d s=f(t) .
$$

Let us change the order of integration and summation

$$
\frac{1}{\Gamma(\beta)} \sum_{i=1}^{n} \sum_{j=0}^{m} a_{j} \int_{\alpha_{i-1}(t)}^{\alpha_{i}(t)} \frac{K_{i}(t, s) s^{j}}{(t-s)^{\beta}} d s=f(t)
$$

and transform the last equality as follows:

$$
\frac{1}{\Gamma(\beta)} \sum_{j=0}^{m} a_{j} \sum_{i=1}^{n} \int_{\alpha_{i-1}(t)}^{\alpha_{i}(t)} \frac{K_{i}(t, s) s^{j}}{(t-s)^{\beta}} d s=f(t) .
$$

We require the fulfillment of the last equality at the points of a uniform grid

$$
t_{k}=\frac{k T}{m+1}, \quad k=1,2, \ldots, m+1 .
$$

Therefore, we arrive at the following system of equations for the unknown coefficients $a_{j}, j=0,1, \ldots, m$ :

$$
\sum_{j=0}^{m} \gamma_{k j} a_{j}=F_{k}, \quad k=1,2, \ldots, m+1
$$

where

$$
\gamma_{k j}=\frac{1}{\Gamma(\beta)} \sum_{i=1}^{n} \int_{\alpha_{i-1}\left(t_{k}\right)}^{\alpha_{i}\left(t_{k}\right)} \frac{K_{i}\left(t_{k}, s\right) s^{j}}{\left(t_{k}-s\right)^{\beta}} d s, \quad F_{k}=f\left(t_{k}\right)
$$

System of linear algebraic equations (8) is solved for unknown expansion coefficients (6) by the Jordan-Gauss method, and in order to calculate the elements of the matrix of this system, below we construct special quadrature formulas that take into account the power singularity of the integrands.

\subsection{Approximation of Weakly Singular Integrals}

In the previous section, when constructing the matrix of system of linear algebraic equations, in order to determine the coefficients of the approximating polynomial, it is necessary to calculate the values of the functions

$$
I(i, k, j)=\int_{\alpha_{i-1}\left(t_{k}\right)}^{\alpha_{i}\left(t_{k}\right)} \frac{K_{i}\left(t_{k}, s\right) s^{j}}{\left(t_{k}-s\right)^{\beta}} d s, \quad i=\overline{1, n}, k=\overline{1, m+1}, j=\overline{0, m},
$$


containing either a convergent improper integral (for $i=n$ ), or significant in magnitude integrands (for $i<n$ ). In this section, we propose a method to calculate integrals (10).

For each triple $i, j, k$, an internal mesh of nodes is constructed as follows:

$$
\tau_{l}=\alpha_{i-1}\left(t_{k}\right)+\frac{l}{r}\left(\alpha_{i}\left(t_{k}\right)-\alpha_{i-1}\left(t_{k}\right)\right), \quad l=0,1, \ldots, r, \quad r=\left[\frac{\alpha_{i}\left(t_{k}\right)-\alpha_{i-1}\left(t_{k}\right)}{h}\right]+1
$$

were $[t]$ stands for integer part of a real number $t$, and $h$ is a sufficiently small parameter, which we conventionally call the grid step. Then we approximate integral (10) as follows:

$$
\begin{gathered}
I(i, k, j)=\sum_{l=1}^{r} \int_{\tau_{l-1}}^{\tau_{l}} \frac{K_{i}\left(t_{k}, s\right) s^{j}}{\left(t_{k}-s\right)^{\beta}} d s \approx \\
\approx \frac{1}{1-\beta} \sum_{l=1}^{r} K_{i}\left(t_{k}, \frac{\tau_{l-1}+\tau_{l}}{2}\right)\left(\frac{\tau_{l-1}+\tau_{l}}{2}\right)^{j}\left(\left(t_{k}-\tau_{l-1}\right)^{1-\beta}-\left(t_{k}-\tau_{l}\right)^{1-\beta}\right) .
\end{gathered}
$$

Therefore, for relatively small values $T$, we propose a sufficiently effective method for solving equations of the form (5), the error of which can be estimated by the inequality

$$
\left\|x(t)-X_{m}(t)\right\|_{C[0, T]} \leq \frac{L_{m+1} T^{m+1}}{(m+1) !}, \quad L=\max _{t \in[0, T]}\left|x^{(m+1)}(t)\right|
$$

for $x(t) \in C^{m+1}[0, T]$.

With an increase in the length of the planning interval $[0, T]$, to maintain the order of accuracy, it is necessary to increase the degrees of the approximating polynomials, which leads to significant computational errors. In order to overcome this restriction, the method can be generalized using a polynomial spline approximation of the solution constructed in each section in a similar way.

It is known that exact solutions to weakly singular Volterra integral equations can have unbounded derivatives as $t \rightarrow 0$ [19]. In this case, the exact solutions belong to the class of functions $C^{r, \beta}(0, T]$ defined as follows.

Definition 11. Let $\Omega=(0, T], 0 \leqslant \beta<1$. We say that a function $x(t)$ belongs to $C^{r, \beta}(0, T]$, if for $t \in(0, T]$ the function $x(t)$ has continuous derivatives up to the order $r$ estimated as follows:

$$
\left|x^{(k)}(t)\right| \leqslant \frac{A_{k}}{t^{k-1+\beta}} \text { for all } t \in(0, T], k=0,1, \ldots, r
$$

In this case, an approximate solution to equation (5) can be found as

$$
X_{m}(t)=a_{0}+\sum_{j=1}^{m} a_{j} t^{j-\beta}
$$

The method to determine coefficients expansion (14) is employed below in the similar way. 
Table 1

Numerical results for Example 1

\begin{tabular}{|c|c|c|c|c|}
\hline \multicolumn{5}{c}{ Errors } \\
\hline $\mathrm{m}$ & $\mathrm{h}=10^{-2}$ & $\mathrm{~h}=10^{-3}$ & $\mathrm{~h}=10^{-4}$ & $\mathrm{~h}=10^{-5}$ \\
\hline 3 & $8,3730 \cdot 10^{-4}$ & $1,0826 \cdot 10^{-3}$ & $1,1168 \cdot 10^{-3}$ & $1,053810^{-3}$ \\
4 & $1,1624 \cdot 10^{-3}$ & $2,0991 \cdot 10^{-4}$ & $1,7066 \cdot 10^{-4}$ & $1,631910^{-4}$ \\
5 & $2,0042 \cdot 10^{-3}$ & $5,3862 \cdot 10^{-5}$ & $6,9064 \cdot 10^{-6}$ & $5,306310^{-6}$ \\
6 & $1,8925 \cdot 10^{-3}$ & $5,3393 \cdot 10^{-5}$ & $1,1764 \cdot 10^{-6}$ & $5,046410^{-7}$ \\
7 & $1,5110 \cdot 10^{-3}$ & $4,6339 \cdot 10^{-5}$ & & $4,380610^{-8}$ \\
8 & $1,8389 \cdot 10^{-3}$ & & & \\
9 & $1,8421 \cdot 10^{-3}$ & & & \\
10 & $7,6494 \cdot 10^{-4}$ & & & \\
\hline
\end{tabular}

\section{Numerical Results}

In order to demonstrate how the numerical method works, we show two examples.

Example 1. As the first example, we solve the following equation:

$$
\frac{1}{\Gamma(\beta)}\left(\int_{0}^{t / 2} \frac{e^{(t+s)} x(s)}{(t-s)^{\beta}} d s+\int_{t / 2}^{2 t / 3} \frac{t s x(s)}{(t-s)^{\beta}} d s+\int_{2 t / 3}^{t} \frac{(s+2)^{3} x(s)}{(t-s)^{\beta}} d s\right)=f(t),
$$

where the right hand side of the equation is chosen such that the exact solution is $\bar{x}(t)=$ $\sin (t)$. Calculations are performed for $t \in[0, T]$, the order of the fractional integration is $\beta=\frac{1}{2}$. Table 1 shows the errors $\varepsilon=\max _{0 \leq i \leq N}\left|\bar{x}\left(t_{i}\right)-X_{m}\left(t_{i}\right)\right|$ for different values of $m$ and $h$.

Example 2. As the second example, we solve the equation

$$
\frac{1}{\Gamma(\beta)}\left(\int_{0}^{\sin \frac{t}{2}} \frac{\sqrt{t+s} x(s)}{(t-s)^{\beta}} d s+\int_{\sin \frac{t}{2}}^{\sin \frac{2 t}{3}} \frac{(t+s) x(s)}{(t-s)^{\beta}} d s+\int_{\sin \frac{2 t}{3}}^{t} \frac{\left(t^{2}+s+3\right) x(s)}{(t-s)^{\beta}} d s\right)=f(t),
$$

where, as well as in the previous example, the right hand side of the equation is chosen such that the exact solution is $\bar{x}(t)=\frac{\ln (t+1) t^{2}}{\sqrt{t}+1}, t \in[0, T]$ and $\beta=\frac{1}{2}$.

Table 2 shows the errors $\varepsilon=\max _{0 \leq i \leq N}\left|\bar{x}\left(t_{i}\right)-X_{m}\left(t_{i}\right)\right|$ for different values of $m$ and $h$.

The examples show the following interesting feature: as the step decreases from $h=$ $10^{-4}$ to $h=10^{-5}$, the error is significantly decreased at Example 1, and remains at the same level at Example 2. Note that the error in the approximate solution to the second model problem is somewhat worse than for the first one. This is due to less smooth components $K_{i}(t, s)$ and a more complex structure of the exact solution. In the future, we intend to develop more accurate quadratures for approximation integrals arising when calculating the coefficients of the system. 
Table 2

Numerical results for Example 2

\begin{tabular}{|c|c|c|c|c|}
\hline \multicolumn{5}{c}{ Errors } \\
\hline $\mathrm{m}$ & $\mathrm{h}=10^{-2}$ & $\mathrm{~h}=10^{-3}$ & $\mathrm{~h}=10^{-4}$ & $\mathrm{~h}=10^{-5}$ \\
\hline 3 & $6,2792 \cdot 10^{-3}$ & $6,3200 \cdot 10^{-3}$ & $6,3211 \cdot 10^{-3}$ & $6,321210^{-3}$ \\
4 & $1,6741 \cdot 10^{-3}$ & $1,7364 \cdot 10^{-3}$ & $1,7370 \cdot 10^{-3}$ & $1,737110^{-3}$ \\
5 & $4,9248 \cdot 10^{-4}$ & $5,3815 \cdot 10^{-4}$ & $5,3845 \cdot 10^{-4}$ & $5,384610^{-4}$ \\
6 & $3,1440 \cdot 10^{-4}$ & $1,9342 \cdot 10^{-4}$ & $1,9291 \cdot 10^{-4}$ & $1,929210^{-4}$ \\
7 & $3,1069 \cdot 10^{-4}$ & $7,9240 \cdot 10^{-5}$ & $8,0305 \cdot 10^{-5}$ & $8,029810^{-5}$ \\
8 & & $3,8965 \cdot 10^{-5}$ & $3,8303 \cdot 10^{-5}$ & $3,829610^{-5}$ \\
9 & & $2,0569 \cdot 10^{-5}$ & $2,0370 \cdot 10^{-5}$ & $2,040610^{-5}$ \\
10 & & $1,0447 \cdot 10^{-5}$ & $1,1771 \cdot 10^{-5}$ & $1,184010^{-5}$ \\
11 & & & $7,4383 \cdot 10^{-6}$ & $7,327710^{-6}$ \\
12 & & & $4,5928 \cdot 10^{-6}$ & $4,767110^{-6}$ \\
13 & & & $3,2945 \cdot 10^{-6}$ & $3,226010^{-6}$ \\
14 & & & $2,7023 \cdot 10^{-6}$ & $2,257110^{-6}$ \\
15 & & & $1,2863 \cdot 10^{-6}$ & $1,622410^{-6}$ \\
\hline
\end{tabular}

\section{Conclusion}

In this article, we present the numerical collocation method that can be used to solve linear Volterra fractional order integral equations of the first kind with piecewise continuous kernel. The proposed quadrature formula effectively employ the restriction of the considered weakly regular equations with fractional order integrals and piecewise continuous kernels.

Acknowledgment. Authors owe a special debt of gratitude to Professor Nikolai A. Sidorov for his generous, thoughtful support and for sharing his vast knowledge.

This work was partially supported by the base part of the Government Assignment for Scientific Research from the Ministry of Science and Higher Education of Russia (project code: FZZS-2020-0039).

\section{References}

1. Linz P. Analytical and Numerical Methods for Volterra Equations. Philadelphia, SIAM, 1985. DOI: $10.1137 / 1.9781611970852$

2. Sidorov D. Volterra Equations of the First Kind with Discontinuous Kernels in the Theory of Evolving Systems Control. Studia Informatica Universalis, 2011, vol. 9, no. 3, pp. 135-146, arXiv: arxiv.org/abs/1111.5903v1.

3. Sidorov D. Integral Dynamical Models: Singularities, Signals and Control. Singapore, London, World Scientific, 2015. DOI: 10.1142/9278

4. Atangana A., Bildik N. The Numerical Solution of the Volterra Fractional Integral Equations of the Second Kind. Mathematical Problems in Engineering, 2013, article ID: 981526, 11 p. DOI: $10.1155 / 2013 / 981526$ 
5. Baleanu D., Diethelm K., Scalas E., Trujillo J.J. Fractional Calculus Models and Numerical Methods. Singapore, World Scientific, 2016. DOI: 10.1142/10044

6. Samko S.G., Kilbas A.A., Marichev O.I. Fractional Integrals and Derivatives: Theory and Applications. Yveron, Gordon and Breach, 1993.

7. Diethelm K., Ford N.J. Analysis of Fractional Differential Equations. Journal of Mathematical Analysis and Applications, 2002, vol. 265, pp. 229-248. DOI: 10.1006/jmaa.2000.7194

8. Diethelm K., Freed A.D. The Frac PECE Subroutine for the Numerical Solution of Differential Equations of Fractional Order. Forschung und wissenschaftliches rechnen, 1998, pp. 57-71.

9. Diethelm K. An Algorithm for the Numerical Solution of Differential Equations of Fractional Order. Electronic Transactions on Numerical Analysis, 1997, vol. 5, pp. 1-6.

10. Sidorov D.N. On Parametric Families of Solutions of Volterra Integral Equations of the First Kind with Piecewise Smooth Kernel. Differential Equations, 2013, vol. 49, no 2, pp. 210-216. DOI: $10.1134 /$ S0012266113020079

11. Sidorov D.N. Solvability of Systems of Volterra Integral Equations of the First Kind with Piecewise Continuous Kernels. Russian Mathematics, 2013, vol. 57, pp. 54-63. DOI: $10.3103 /$ S1066369X13010064

12. Sidorov N.A., Sidorov D.N. On the Solvability of a Class of Volterra Operator Equations of the First Kind with Piecewise Continuous Kernels. Mathematical Notes, 2014, vol. 96, pp. 811-826. DOI: $10.4213 / \mathrm{mzm} 10220$

13. Muftahov I., Tynda A., Sidorov D. Numeric Solution of Volterra Integral Equations of the First Kind with Discontinuous Kernels. Journal of Computational and Applied Mathematics, 2017, vol. 313, pp. 119-128. DOI: 10.1016/j.cam.2016.09.003

14. Sidorov D., Tynda A., Muftahov I., Dreglea A., Liu F. Nonlinear Systems of Volterra Equations with Piecewise Smooth Kernels: Numerical Solution and Application for Power Systems Operation. Mathematics, 2020, vol. 8, no. 8, pp. 1257. DOI: 10.3390/math8081257

15. Sidorov D., Muftahov I., Tomin, N., Karamov D., Panasetsky D., Dreglea A., Liu F. A Dynamic Analysis of Energy Storage with Renewable and Diesel Generation Using Volterra Equations. IEEE Transactions on Industrial Informatics, 2020, vol. 16, no. 5, article ID: 8784402, pp. 3451-3459. DOI: 10.1109/TII.2019.2932453

16. Sidorov D., Panasetsky D., Tomin N., Karamov D., Zhukov A., Muftahov I., Dreglea A., Liu F., Li Y. Toward Zero-Emission Hybrid AC/DC Power Systems with Renewable Energy Sources and Storages: A Case Study from Lake Baikal Region. Energies, 2020, vol. 13, no. 5, pp. 1226. DOI: $10.3390 /$ en13051226

17. Sidorov N., Sidorov D., Sinitsyn A. Toward General Theory of Differential-Operator and Kinetic Models. Singapore, London, World Scientific, 2020. DOI: 10.1142/11651

18. Sizikov V., Sidorov D. Generalized Quadrature for Solving Singular Integral Equations of Abel Type in Application to Infrared Tomography. Applied Numerical Mathematics, 2016, vol. 106, pp. 69-78. DOI: 10.1016/j.apnum.2016.03.004

19. Brunner H., Pedas A., Vainikko G. The Piecewise Polynomial Collocation Method for Nonlinear Weakly Singular Volterra Equation. Mathematics of Computation, 1999, vol. 68, no. 227, pp. 1079-1095. DOI: 10.1090/S0025-5718-99-01073-X

Received October 5, 2020 


\title{
ЧИСЛЕННЫЙ АНАЛИЗ ДРОБНЫХ ИНТЕГРАЛЬНЫХ ДИНАМИЧЕСКИХ МОДЕЛЕЙ С КУСОЧНО-НЕПРЕРЫВНЫМИ ЯДРАМИ
}

\author{
А.Н. Тында ${ }^{1}$, Д.Н. Сидоров ${ }^{2,3}$, И.Р. Муфтахов ${ }^{2,4}$ \\ ${ }^{1}$ Пензенский государственный университет, г. Пенза, Российская Федерация \\ ${ }^{2}$ Институт систем энергетики имени Л.А. Мелентьева СО РАН, г. Иркутск, \\ Российская Федерация \\ ${ }^{3}$ Иркутский национальный исследовательский технический университет, г. Иркутск, \\ Российская Федерация \\ ${ }^{4}$ Главный вычислительный центр ОАО «РЖКД», г. Иркутск, Российская Федерация
}

\begin{abstract}
Интегральные уравнения Вольтерра находят свое применение во многих областях, включая математическую физику, теорию управления, механику, электротехнику, и в различных отраслях промышленности. В частности, динамические модели Вольтерра с разрывными ядрами эффективно используются в энергетике для определения режимов работы накопителей энергии, а также для решения задачи выравнивания нагрузки. В статье предлагается численный метод решения линейных интегральных уравнений Вольтерра первого рода дробного порядка интегрирования с кусочно-непрерывными ядрами. Разработанный подход основан на методе полиномиальной коллокации и эффективно аппроксимирует такие слабо сингулярные интегралы. Эффективность предложенного численного метода иллюстрируется на двух примерах.
\end{abstract}

Ключевые слова: интегралъные уравнения Вольтерра; численный метод; сходимость; сингулярность; дробный интеграл.

Александр Николаевич Тында, кандидат физико-математических наук, доцент кафедры высшей и прикладной математики, Пензенский государственный университет (г. Пенза, Российская Федерация), tyndaan@mail.ru.

Денис Николаевич Сидоров, доктор физико-математических наук, профессор PАН, главный научный сотрудник, Институт систем энергетики имени Л.А. Мелентьева СО РАН (г. Иркутск, Российская Федерация); Иркутский национальный исследовательский технический университет, Байкальский институт БРИКС (г. Иркутск, Российская Федерация), contact.dns@gmail.com.

Ильдар Ринатович Муфтахов, Институт систем энергетики имени Л.А. Мелентьева СО РАН; Иркутский информационно-вычислительный центр, Главный вычислительный центр ОАО «РЖД» (г. Иркутск, Российская Федерация), ildar_sm@mail.ru.

Поступила в редакцию 5 октября 2020 г. 